\title{
Los factores que explican la mayor aglomeración de la industria de alta tecnología en la frontera norte de México: el caso de Matamoros y Reynosa
}

\section{The factors that explain the major agglomeration of the industry of high technology in the north border of Mexico: the case of Matamoros and Reynosa}

Jorge Alberto Pérez Cruz, * Guadalupe Isabel Ceballos Álvarez* y Adolfo Rogelio Cogco Calderón*

\section{Resumen}

En las últimas tres décadas, la distribución geográfica de la manufactura provocó nuevas concentraciones en la industria de alta tecnología. Este estudio analiza desde las externalidades pecuniarias y tecnológicas hasta los factores del cambio en la aglomeración de dicha industria. Se aplicó un cuestionario a 55 establecimientos en Matamoros y Reynosa, en Tamaulipas. Los resultados denotan que la mayor concentración de la industria fue motivada por la ubicación geográfica de los municipios, el acceso a mano de obra no calificada y barata, y la disponibilidad de infraestructura urbana, entre otros. No hay, pues, evidencia a favor de que las externalidades pecuniarias y tecnológicas determinasen la aglomeración de la industria de alta tecnología en estas ciudades.

Palabras clave: manufactura, alta tecnología, aglomeración y externalidades. JEL: C83, R11, R12, L62, L63.

Recibido el 31 de julio de 2013.

Aprobado el 11 de noviembre de 2013.

\section{Abstract}

In the last three decades the geographical distribution of manufacturing change substantially, prompting new concentrations, particularly in the high tech industry. In this sense, the aim of this study is to know and analyze from the perspective of pecuniary and technological externalities factors that explain the change in the agglomeration of high-tech manufacturing. To do so, a questionnaire was applied to 55 manufacturing facilities located in Matamoros and Reynosa in Tamaulipas. The results indicate that the highest concentration of hightech industry has been motivated mainly by the geographic location of the municipalities, access to unskilled labor and cheap availability of urban infrastructure, among others. This means that there is no evidence for the pecuniary and technological externalities determine the agglomeration of high-tech industry in these cities.

Keywords: manufacturing, high-tech, agglomeration and externalities. JEL: C83, R11, R12, L62, L63.

* Profesores-investigadores de la Universidad Autónoma de Tamaulipas. Centro Universitario Tampico-Madero. Correos electrónicos: jperezc@uat.edu.mx; gica_79@hotmail.com; acogco@uat.edu.mx 


\section{El cambio en la concentración de la industria manufacturera en México}

En las tres décadas recientes se evidencian cambios en la distribución geográfica de la industria manufacturera en México. Para contextualizar estos cambios se presenta la distribución porcentual de la industria por estado durante el periodo 1981-2009. Para lograr tal fin, se realizó el cálculo utilizando el número de trabajadores en lugar del número de unidades económicas (como una aproximación a las firmas), dado que al desagregar la industria manufacturera a nivel de clase, el número de unidades económicas de diversas industrias no es posible conocerlo. La información que se presenta en el cuadro 1 se construyó con base en datos de los censos económicos que publica el Instituto Nacional de Estadística y Geografía (INEGI).

Al final del cuadro 1 se aprecia la consistente tendencia a decrecer de la desviación estándar, lo que refleja el evidente cambio en la estructura espacial de la industria manufacturera a través de los estados. Al inicio del periodo de análisis, $60 \%$ de la industria se concentraba en sólo cuatro estados: México, Jalisco, Nuevo León y Distrito Federal. El otro $40 \%$ de la industria estaba distribuido entre los restantes 28 estados. Los datos en 2009 exponían una situación distinta para estos estados, ya que únicamente concentraban $36 \%$ de la manufactura, su nivel más bajo durante el periodo de análisis. Por su parte, Baja California, Coahuila, Chihuahua, Guanajuato, Sonora y Tamaulipas son los estados que incrementaron su participación en la industria manufacturera de manera sustancial. En 1981 concentraban un poco más de $14 \%$ de la industria mientras que para 2009 concentraron $32 \%$. Los estados que incrementaron de manera significativa su participación en la industria fueron principalmente los fronterizos del norte. En esta zona, contemplando a Nuevo León, se concentra cerca de $34 \%$ de todo el personal ocupado de la industria manufacturera que hay en México. El estado que mayor crecimiento manifestó en estas tres décadas es Baja California, seguido de Chihuahua y, posteriormente, Tamaulipas. Lo anterior refleja que el sector manufacturero ha estado concentrado y continúa haciéndolo.

En el cuadro 2 se muestra la distribución absoluta y porcentual de la industria manufacturera, electrónica, eléctrica y del transporte para los 
Cuadro 1. Distribución porcentual del personal ocupado total de la industria manufacturera por estados: Periodo 1981-2009

\begin{tabular}{|c|c|c|c|c|c|c|c|}
\hline Estado & 1981 & 1986 & 1989 & 1994 & 1999 & 2004 & 2009 \\
\hline Aguascalientes & $0.8 \%$ & $1.2 \%$ & $1.3 \%$ & $1.5 \%$ & $1.6 \%$ & $1.6 \%$ & $1.6 \%$ \\
\hline Baja California & $2.0 \%$ & $2.2 \%$ & $3.0 \%$ & $4.3 \%$ & $5.9 \%$ & $6.0 \%$ & $6.0 \%$ \\
\hline Baja California Sur & $0.1 \%$ & $0.2 \%$ & $0.2 \%$ & $0.3 \%$ & $0.3 \%$ & $0.2 \%$ & $0.2 \%$ \\
\hline Campeche & $0.2 \%$ & $0.2 \%$ & $0.2 \%$ & $0.3 \%$ & $0.2 \%$ & $0.3 \%$ & $0.4 \%$ \\
\hline Coahuila de Zaragoza & $2.8 \%$ & $3.5 \%$ & $4.1 \%$ & $3.9 \%$ & $4.5 \%$ & $5.1 \%$ & $4.3 \%$ \\
\hline Colima & $0.2 \%$ & $0.2 \%$ & $0.2 \%$ & $0.2 \%$ & $0.2 \%$ & $0.3 \%$ & $0.3 \%$ \\
\hline Chiapas & $0.5 \%$ & $0.6 \%$ & $0.7 \%$ & $0.8 \%$ & $0.7 \%$ & $0.8 \%$ & $1.0 \%$ \\
\hline Chihuahua & $2.9 \%$ & $4.8 \%$ & $6.5 \%$ & $6.9 \%$ & $8.4 \%$ & $8.4 \%$ & $7.4 \%$ \\
\hline Distrito Federal & $27.3 \%$ & $21.0 \%$ & $18.9 \%$ & $15.5 \%$ & $11.8 \%$ & $10.7 \%$ & $8.7 \%$ \\
\hline Durango & $1.1 \%$ & $0.6 \%$ & $1.7 \%$ & $1.5 \%$ & $1.6 \%$ & $1.7 \%$ & $1.3 \%$ \\
\hline Guanajuato & $3.1 \%$ & $4.2 \%$ & $4.5 \%$ & $4.9 \%$ & $5.5 \%$ & $5.3 \%$ & $5.8 \%$ \\
\hline Guerrero & $0.5 \%$ & $0.5 \%$ & $0.5 \%$ & $0.8 \%$ & $0.9 \%$ & $1.0 \%$ & $1.2 \%$ \\
\hline Hidalgo & $2.2 \%$ & $1.8 \%$ & $1.6 \%$ & $1.7 \%$ & $1.7 \%$ & $1.7 \%$ & $1.9 \%$ \\
\hline Jalisco & $6.9 \%$ & $10.3 \%$ & $6.6 \%$ & $6.9 \%$ & $7.7 \%$ & $7.8 \%$ & $8.1 \%$ \\
\hline México & $17.1 \%$ & $15.4 \%$ & $14.4 \%$ & $13.1 \%$ & $11.6 \%$ & $10.8 \%$ & $11.4 \%$ \\
\hline Michoacán de Ocampo & $1.4 \%$ & $1.8 \%$ & $2.1 \%$ & $2.0 \%$ & $1.9 \%$ & $2.0 \%$ & $2.4 \%$ \\
\hline Morelos & $1.1 \%$ & $1.1 \%$ & $1.1 \%$ & $1.2 \%$ & $1.0 \%$ & $1.1 \%$ & $1.1 \%$ \\
\hline Nayarit & $0.4 \%$ & $0.3 \%$ & $0.4 \%$ & $0.5 \%$ & $0.3 \%$ & $0.3 \%$ & $0.3 \%$ \\
\hline Nuevo León & $9.1 \%$ & $7.7 \%$ & $7.8 \%$ & $7.8 \%$ & $7.7 \%$ & $7.7 \%$ & $7.7 \%$ \\
\hline Oaxaca & $0.7 \%$ & $0.9 \%$ & $1.1 \%$ & $1.2 \%$ & $1.2 \%$ & $1.2 \%$ & $1.5 \%$ \\
\hline Puebla & $4.5 \%$ & $4.2 \%$ & $4.2 \%$ & $4.9 \%$ & $5.3 \%$ & $5.0 \%$ & $5.0 \%$ \\
\hline Querétaro de Arteaga & $2.1 \%$ & $1.9 \%$ & $1.9 \%$ & $1.9 \%$ & $2.2 \%$ & $2.2 \%$ & $2.6 \%$ \\
\hline Quintana Roo & $0.1 \%$ & $0.2 \%$ & $0.2 \%$ & $0.2 \%$ & $0.2 \%$ & $0.2 \%$ & $0.3 \%$ \\
\hline San Luis Potosí & $1.4 \%$ & $1.8 \%$ & $2.0 \%$ & $2.0 \%$ & $1.8 \%$ & $2.1 \%$ & $2.3 \%$ \\
\hline Sinaloa & $1.0 \%$ & $1.3 \%$ & $1.0 \%$ & $1.2 \%$ & $0.9 \%$ & $1.1 \%$ & $1.3 \%$ \\
\hline Sonora & $1.8 \%$ & $2.0 \%$ & $2.5 \%$ & $2.6 \%$ & $3.3 \%$ & $3.0 \%$ & $3.4 \%$ \\
\hline Tabasco & $0.4 \%$ & $0.5 \%$ & $0.6 \%$ & $0.6 \%$ & $0.5 \%$ & $0.5 \%$ & $0.5 \%$ \\
\hline Tamaulipas & $2.1 \%$ & $2.7 \%$ & $3.8 \%$ & $4.5 \%$ & $4.5 \%$ & $5.0 \%$ & $5.0 \%$ \\
\hline Tlaxcala & $0.9 \%$ & $1.1 \%$ & $1.0 \%$ & $1.0 \%$ & $1.3 \%$ & $1.2 \%$ & $1.2 \%$ \\
\hline Veracruz-Llave & $3.7 \%$ & $4.7 \%$ & $4.4 \%$ & $3.3 \%$ & $3.1 \%$ & $3.0 \%$ & $3.0 \%$ \\
\hline Yucatán & $1.3 \%$ & $1.1 \%$ & $1.2 \%$ & $1.7 \%$ & $1.7 \%$ & $2.0 \%$ & $1.9 \%$ \\
\hline Zacatecas & $0.3 \%$ & $0.2 \%$ & $0.3 \%$ & $0.5 \%$ & $0.6 \%$ & $0.6 \%$ & $0.6 \%$ \\
\hline Desviación estándar & 5.4 & 4.5 & 4.1 & 3.6 & 3.2 & 3.1 & 2.9 \\
\hline
\end{tabular}

Fuente: Elaboración propia con base en datos de los censos industriales de 1981, 1986 y 1989, y los censos económicos de 1994, 1999, 2004 y 2009. 


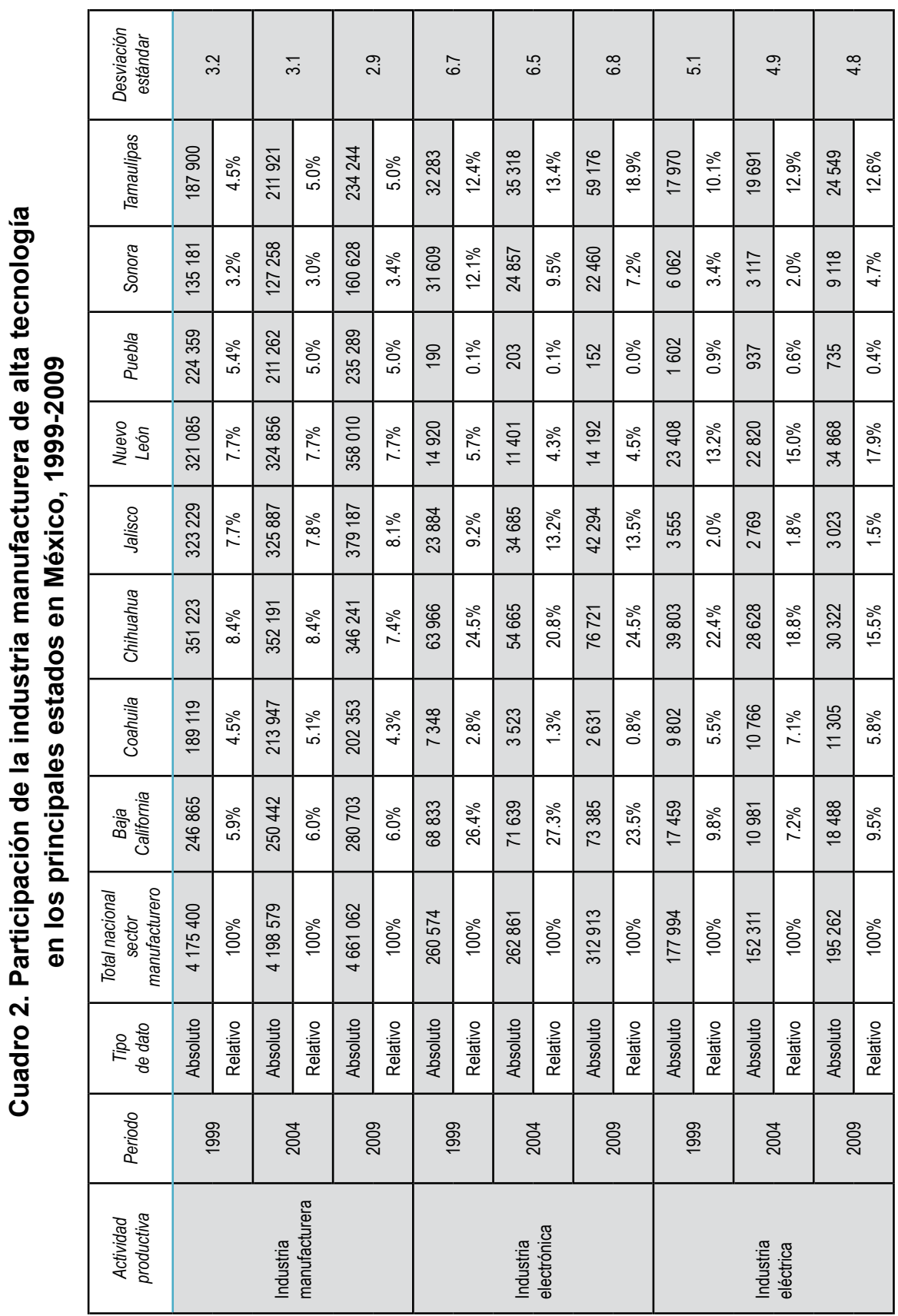


Estudios Fronterizos, nueva época, vol. 15, núm. 29, enero-junio de 2014

\begin{tabular}{|c|c|c|c|c|c|}
\hline \multicolumn{2}{|c|}{ مٌ } & \multicolumn{2}{|c|}{0} & \multicolumn{2}{|c|}{$\stackrel{\forall}{\forall}$} \\
\hline $\begin{array}{l}\text { ర్ } \\
\text { ద్ల }\end{array}$ & $\begin{array}{c}\stackrel{0}{0} \\
\infty\end{array}$ & \begin{tabular}{l}
\multirow{J}{*}{} \\
$\tilde{y}$ \\
$\tilde{y}$
\end{tabular} & $\begin{array}{l}\stackrel{0}{0} \\
\infty \\
\infty\end{array}$ & $\begin{array}{l}\text { ஜ } \\
8 \\
\text { \&f }\end{array}$ & $\begin{array}{l}\stackrel{0}{\circ} \\
\infty \\
\infty\end{array}$ \\
\hline$\frac{8}{\stackrel{\oplus}{\sigma}}$ & $\begin{array}{l}\stackrel{\circ}{+} \\
\stackrel{+}{*}\end{array}$ & $\begin{array}{l}\hat{N} \\
\text { 을 }\end{array}$ & $\begin{array}{l}\stackrel{\circ}{\circ} \\
\oplus^{\circ}\end{array}$ & 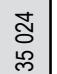 & $\begin{array}{l}\stackrel{\circ}{\circ} \\
\text { i }\end{array}$ \\
\hline $\begin{array}{l}\& \\
\& \\
\stackrel{\circ}{N}\end{array}$ & $\frac{\circ}{\circ}$ & $\begin{array}{l}\text { 今. } \\
\stackrel{0}{\sim}\end{array}$ & $\begin{array}{l}\circ \\
\stackrel{\circ}{\circ}\end{array}$ & $\begin{array}{l}\mathbb{N} \\
\mathbb{R} \\
0 \\
0\end{array}$ & $\begin{array}{l}\stackrel{0}{\circ} 0 \\
0 \\
0\end{array}$ \\
\hline 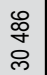 & ১̊̀ & $\begin{array}{l}8 \\
\stackrel{0}{0} \\
\stackrel{్}{0}\end{array}$ & $\stackrel{\circ}{\stackrel{\circ}{\sim}}$ & 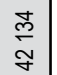 & $\stackrel{\circ}{\stackrel{\circ}{\circ}}$ \\
\hline $\begin{array}{l}\bar{\aleph} \\
\text { O }\end{array}$ & $\underset{\stackrel{\sim}{\sim}}{\stackrel{\sim}{\sim}}$ & 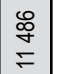 & ণิ & $\begin{array}{l}\stackrel{R}{N} \\
F\end{array}$ & ৯ิ \\
\hline 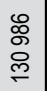 & $\stackrel{\circ}{\check{\check{c}}}$ & $\begin{array}{l}\hat{m} \\
\overleftarrow{\emptyset}\end{array}$ & 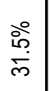 & 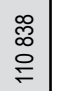 & 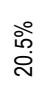 \\
\hline $\begin{array}{l}\stackrel{L}{N} \\
\stackrel{8}{q}\end{array}$ & $\stackrel{\stackrel{\circ}{\mathrm{m}}}{\risingdotseq}$ & $\begin{array}{l}\stackrel{\circ}{m} \\
\stackrel{\sim}{n}\end{array}$ & 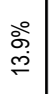 & $\begin{array}{l}8 \\
\stackrel{8}{8} \\
8 \\
6\end{array}$ & 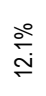 \\
\hline $\begin{array}{l}\bar{\sigma} \\
\frac{\sigma}{\sigma}\end{array}$ & స్ల & $\begin{array}{l}\stackrel{+}{D} \\
\stackrel{f}{f}\end{array}$ & 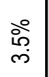 & 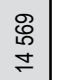 & 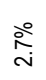 \\
\hline 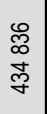 & ळे & 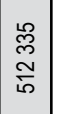 & ઠे̊ & $\begin{array}{l}0 \\
\stackrel{5}{0} \\
\stackrel{8}{0}\end{array}$ & ○े \\
\hline 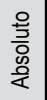 & 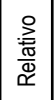 & $\begin{array}{l}\text { 옿 } \\
\frac{0}{0} \\
\frac{0}{<}\end{array}$ & 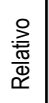 & 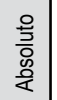 & 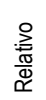 \\
\hline ‡ & 忽 & ๙ీ & & 을 & \\
\hline & & 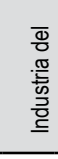 & & & \\
\hline
\end{tabular}


Jorge Pérez, Guadalupe Ceballos, y Adolfo Cogco/Los factores que explican la mayor aglomeración

ocho estados que mayor concentración tienen en estas industrias en los tres últimos censos económicos. Analizando el valor de la desviación estándar como un referente en cuanto al grado de concentración de la industria electrónica, eléctrica y del transporte a través de los estados, se puede destacar que es muy superior al obtenido en la industria manufacturera, lo que significa que estas tres industrias se encuentran concentradas en pocos estados en México. En lo que se refiere a la industria electrónica, se observa que tiene la mayor desviación estándar, en consecuencia, es la que denota un nivel de concentración mayor; de hecho, en una década creció ligeramente su nivel de concentración. Al comparar la desviación estándar de esta industria con la obtenida en 1981 en el cuadro 2, periodo en el cual alcanzó el mayor nivel de concentración la industria manufacturera en su conjunto, se aprecia que es muy superior. La industria electrónica para 2009 se localizó principalmente en Baja California (23.5\%), Chihuahua (24.5\%), Jalisco (13.5\%) y Tamaulipas (18.9\%); es decir $80 \%$ se localizó tan sólo en estos cuatro estados. Aunque cabe hacer mención que es en el estado de Tamaulipas donde principalmente creció la participación de esta industria, alcanzando una tasa de $52 \%$ de 1999 a 2009.

Revisando el nivel de concentración de la industria eléctrica, resulta que ésta es la segunda en importancia de acuerdo con la desviación estándar, aunque a diferencia de la industria electrónica, se observa una tendencia a desconcentrarse, ya que en 1999 se tenía un valor de 5.1 y en 2009 éste disminuyó a 4.8. Los estados donde principalmente se concentró esta industria en 2009 son Baja California (9.5\%), Chihuahua (15.5\%), Nuevo León (17.9\%) y Tamaulipas (12.6\%); es decir, en conjunto estos estados aglomeraron $55 \%$ de toda la industria eléctrica del país. Chihuahua ha disminuido de manera significativa su participación en esta industria, mientras que Nuevo León y Tamaulipas han incrementado su participación. El caso de Baja California se ha mantenido relativamente estable durante el periodo de análisis.

En cuanto a la industria de equipo de transporte, dedicada a la fabricación de automóviles, carrocerías, partes para vehículos, equipo aeroespacial, ferroviario, embarcaciones y otros, se observa que en el periodo de 2009 es la menos concentrada, en comparación con la electrónica y eléctrica. Aunque durante el periodo de 1999 a 2004 se observó que la industria tendía a estar más concentrada entre los estados, esa tendencia 
se desvirtuó para 2009. Los estados donde principalmente se localiza este tipo de industria son Coahuila (12.1\%), Chihuahua (20.5\%), Nuevo León (7.8\%) y Tamaulipas $(8.3 \%)$, que en total aglomeran $49 \%$ en 2009 . Como se observa, esta industria se concentra principalmente en el estado de Chihuahua; sin embargo, la hegemonía que poseía este estado en 1999, ha disminuido de manera considerable, ya que en 1999 concentraba $30 \%$ de toda la industria; es decir, su participación ha disminuido en $31 \%$ en una década.

Por otro lado, no se encuentra evidencia que permita establecer que la pérdida en la participación de Chihuahua fuera absorbida por algún estado en específico; más bien se justifica el bajo valor de la desviación estándar, lo que significa que la industria distribuye su participación de manera más equitativa entre los estados.

Bajo este escenario de análisis de la concentración de la industria electrónica, eléctrica y del transporte es posible establecer que es la industria electrónica la que muestra indicadores más sólidos en cuanto al nivel de concentración, lo que refleja a una industria con una tendencia a estar altamente concentrada en pocos espacios territoriales. También la industria eléctrica y del transporte requieren estar concentradas, aunque en menor medida que la electrónica.

En este sentido, al analizar los cambios en la distribución de la industria de los tres principales estados (Baja California, Chihuahua y Tamaulipas), se observó que las que más se aglomeran elaboran productos de media y alta tecnología, de acuerdo con la clasificación de la Organización para la Cooperación y el Desarrollo Económicos (OCDE) y Eurostat (2005). Tamaulipas es el tercer estado en donde más creció esta industria, después de Baja California y Chihuahua, respectivamente. Además, se observa que ha sido en Tamaulipas donde se ha incrementado el nivel de especialización en éstas. Al interior del estado, dos son los municipios que se han consolidado en actividades manufactureras de alta tecnología: Matamoros y Reynosa, ya que en conjunto concentran $65 \%$ de la industria eléctrica, electrónica y del transporte. Las industrias que destacan son las que se dedican a la fabricación de computadoras y equipo periférico, equipo de audio y de video, componentes electrónicos, aparatos eléctricos de uso doméstico, motores y generadores eléctricos, y equipo eléctrico y electrónico para vehículos automotores. 
El municipio de Reynosa se ha especializado en la industria electrónica, mientras que Matamoros ha hecho lo propio en la industria del transporte. En el caso de Reynosa, se observa que la industria que principalmente se ha especializado es la de computadoras y equipo periférico, pero aunque su indicador es alto, tiene una tendencia a decrecer. Además, en la industria eléctrica también se observa que el municipio ha alcanzado un nivel de especialización importante, específicamente en la fabricación de motores y generadores eléctricos. Para Matamoros, la industria que fabrica equipo eléctrico y electrónico para vehículos automotores creció de forma significativa, lo que provocó que en 2009 el municipio se especializara en esta industria; mientras que por otro lado la menor presencia de industria electrónica tuvo como consecuencia que el nivel de especialización que había alcanzado en 1999 cayera drásticamente para 2009.

Al comparar el grado de concentración de tres industrias de alta tecnología establecidas en Tamaulipas con el resto de las actividades industriales manufactureras que se desarrollan en cada unidad geográfica analizada, se estableció que son la industria electrónica y la del transporte las que más se concentran. Situación muy similar a la observada en el análisis a escala nacional. ${ }^{1}$

El hecho de que se observen cambios en la concentración de la totalidad de la industria manufacturera, y que derivado de estos cambios se tenga una industria de alta tecnología más concentrada, conlleva a cuestionarse qué factores han provocado una mayor aglomeración de esta industria en la frontera norte de México. Para responder esta cuestión, es necesario realizar un análisis más específico y profundo sobre las condiciones que han promovido dicha situación. La evidencia teóricaempírica deja entrever que en estas industrias se pueden observar las ventajas territoriales que generan los encadenamientos productivos, los procesos de innovación que promueven a nivel regional, la investigación y desarrollo, el trabajo especializado y altamente capacitado, y la transferencia de tecnología y del conocimiento, entre otros (Dávila, 2004; Ellison y Glaeser, 1999; Fujita y Thise, 2002; De la Garza, 2004; Dutrénit y VeraCruz, 2009; Galbraith, De Noble y Estavillo, 1990; Hanson, 1994; Koo, 2005; Krugman, 1991 y 1998; Mendoza y Pérez, 2007). Cada uno de ellos

${ }^{1}$ La información se encuentra disponible para quien lo requiera. 
representa un componente fundamental en el crecimiento y desarrollo económico, tanto para otras industrias manufactureras como para el resto de las actividades económicas (Kaldor, 1970).

Aunque en su mayoría la industria de alta tecnología localizada en la frontera norte es maquiladora de exportación, la evidencia muestra que esta industria ha evolucionado, transitando de un modelo de ensamble tradicional especializado en mano de obra no calificada, a un modelo con proceso de producción automatizado e intensivo, en mano de obra calificada, donde se realizan actividades de investigación, diseño y desarrollo tecnológico (Carrillo y Gomis, 2004; De la Garza, 2004; Dutrénit y VeraCruz, 2009).

Cabe resaltar que resulta importante comprender los factores que influyen en la localización de la industria de alta tecnología ya que esta industria es muy sensible a cambios en la competitividad de las regiones y con facilidad puede re-localizarse a lugares con mejores perspectivas de crecimiento y desarrollo (Galbraith et al., 1990; Mendoza y Pérez, 2007).

En este sentido, el propósito del presente trabajo es analizar e identificar los factores que explican la aglomeración de la industria de alta tecnología en la frontera norte de México, específicamente en los municipios de Reynosa y Matamoros del estado de Tamaulipas, a partir de la propuesta de un esquema teórico basado en las externalidades pecuniarias y tecnológicas.

Para llevar a cabo el análisis sobre los factores determinantes de la localización de la industria de alta tecnología en la ciudad de Matamoros y Reynosa, se aplicó el cuestionario a un conjunto de establecimientos manufactureros pertenecientes a la industria electrónica, eléctrica y del transporte durante el periodo de 2010 a 2011.

Este trabajo de investigación se divide en cinco partes: en la primera se contextualiza la situación de la industria de alta tecnología en México; en la segunda se plantea el esquema teórico que permite comprender desde una visión de las externalidades los factores que determinan la localización de la industria de alta tecnología en un espacio específico; posteriormente, se muestra la metodología del instrumento para recabar la información de las plantas de producción; y en el siguiente apartado se muestran los resultados obtenidos de la aplicación del cuestionario a los establecimientos manufactureros de la industria de alta tecnología; finalmente se plantean las conclusiones del trabajo. 


\section{Las externalidades pecuniarias y tecnológicas como determinantes de la aglomeración de la industria manufacturera de alta tecnología}

La relevancia de la industria manufacturera recae en los beneficios que surgen cuando se concentra geográficamente. La teoría de la localización y la Nueva Geografía Económica (NGE), arropadas por las corrientes del desarrollo regional, han contribuido de manera significativa en el entendimiento de las razones que llevan a la industria a concentrarse. Para la escuela alemana, la concentración de la industria se explica a partir de la dimensión del mercado para el producto final y por el costo de producción en referencia a la localización de los insumos (Lösch, 1954; Weber, 1929). Para esta escuela las economías de aglomeración aparecen de la dimensión de la concentración de la industria. Este punto es retomado por la NGE asumiendo que la concentración de la industria se asocia de forma directa sobre los beneficios que genera vía las economías externas, un argumento asociado a las externalidades marshallianas (Krugman, 1991). A diferencia de la escuela alemana, los beneficios del acceso al mercado laboral denso y diversificado, la derrama de conocimientos y los encadenamientos productivos surgen de la dimensión e interacción de la industria ubicada en un mismo espacio.

En el modelo de la geografía económica, las economías externas mejoran la escala de producción de la industria o industrias, lo que provoca que las firmas puedan beneficiarse al tener un mercado especializado o diversificado que les permite mejorar el acceso a productos de otras firmas, los cuales son internalizados como insumos directos (mercado especializado) o indirectos (mercado diversificación) o viceversa. Entonces, la magnitud de las economías externas depende del nivel de aglomeración de la industria. Fujita, Krugman y Venables (1999) exponen la forma en que interactúan las economías externas y la dimensión de la aglomeración. Asumen que existe una relación en forma de u invertida entre estas dos variables, por lo que en la parte inicial de la aglomeración de la industria en el espacio, el tipo de relación que se observa entre estas variables es positiva. Así, en esta fase las ciudades se industrializan dado que la escala de producción de la industria favorece la creación de nuevos establecimientos que producen tanto con rendimientos crecientes como decrecientes. 
Mientras que en la fase donde la relación entre las economías externas y la aglomeración industrial se asume negativa, la escala de producción de la industria sólo permite la aglomeración de firmas que presentan rendimientos crecientes. Esta última condición se presenta en ciudades donde la excesiva aglomeración de la industria genera costos que merman los beneficios de las economías externas. Cuando los impactos de la aglomeración de la industria sobre las economías externas son adversos, la industria se re-localiza en lugares con mejores ventajas espaciales, generándose así la creación de nuevas ciudades industriales.

Para entender mejor la dinámica de aglomeración de la industria, Fujita y colaboradores (1999) desarrollan y analizan un modelo urbano que permite visualizar la distribución, el tamaño y los tipos de áreas urbanas. Dos resultados se derivan de este modelo: por un lado, la relación entre las economías externas asociadas con la aglomeración de la industria en la ciudad; y por otro, el surgimiento de las deseconomías que afrontan los trabajadores conforme la industria más se aglomera, tales como el costo de trasladarse de su casa al trabajo - tanto en tiempo como en transporte- y el crecimiento de los costos de bienes y servicios locales - aquellos donde su acceso se limita localmente y que por lo tanto no se pueden sustituir por algún otro en una ciudad o región distinta-, afectando el costo de vida de la población (Chatterjee, 2003).

De esta manera, la aglomeración de la industria por las economías externas genera progresivamente que el costo de vida de la población se incremente, lo que lleva a que se demanden mayores salarios, por lo que el efecto del mayor costo de vida de la población se traslada a las firmas, enfrentando mayores salarios, los cuales se confrontan con los beneficios que generan las economías externas. El efecto dependerá del nivel de rendimientos que presente cada sector, aunque los sectores con mejores rendimientos crecientes pueden continuar aglomerándose en presencia de salarios altos. Ellison y Glasear (1999) proveen evidencia empírica respecto de que en las ciudades con grandes aglomeraciones de industria el costo de vida y los salarios son más altos que en el resto de las ciudades donde la concentración es menor.

En este sentido, la NGE supone rendimientos crecientes a escala en la producción a un nivel agregado de las empresas (economías externas). En ausencia de éstos, los productores podrían localizarse en cualquier otra 
ciudad. Entonces, la dinámica de aglomeración de la industria evoluciona bajo el precepto de economías externas, donde ésta puede manifestarse a través de las externalidades pecuniarias y/o tecnológicas. Tanto las externalidades pecuniarias como las tecnológicas aparecen de las relaciones entre firmas de una industria o varias industrias; sin embargo, el impacto de estas externalidades, al ser internalizadas por las firmas, es distinto. En el caso de las pecuniarias, influye en el mecanismo de precios del mercado debido a las relaciones input-output de las firmas y la disponibilidad de un mercado laboral, mientras que las tecnológicas benefician a las firmas de manera informal a través de la innovación en proceso y diseño de los productos; es decir, se presenta un fenómeno conocido como "derrama de conocimiento". En el caso de esta última externalidad, ha sido poca la evidencia empírica que existe, siendo la principal razón su carácter informal e intangible, por lo que resulta complejo dimensionar su efecto sobre la aglomeración de la industria (Fujita y Thise, 2002).

Estas externalidades surgen debido a que al concentrarse la industria en un espacio se genera un mercado donde se accede a insumos de otras firmas y/o para vender los productos de una firma que son utilizados como insumos en otros procesos productivos de otras firmas en la industria. Como consecuencia de lo anterior, se genera un mercado especializado donde, por un lado, se puede subcontratar a otras firmas que realicen alguna fase del proceso productivo y, por otro, se puede acceder a mano de obra especializada, ya que los trabajadores capacitados en ciertas áreas de la industria se establecerán donde se concentre la industria; también las firmas deciden localizarse para conocer las innovaciones tanto en producto como en diseño que las otras firmas realizan a sus productos y de esta manera estar a la vanguardia tecnológica y mantener el nivel de competitividad, esto se conoce como "derrama tecnológica" (Koo, 2005).

Koo (2005) retoma los planteamientos de la escuela clásica alemana sobre la localización y las externalidades propuestas por Marshall (1920) para definir los determinantes de la aglomeración industrial en dos vertientes. Por una parte, las externalidades pecuniarias que surgen de la interacción comercial entre las firmas, por lo que afectan el mecanismo de precios. Por otra parte, se encuentran las externalidades tecnológicas que, por el contrario, no se originan por la interacción de mercado, sino más bien por la proximidad espacial de las firmas. Respecto de la primera, se 
incluyen dos de las tres externalidades de Marshall (1920), la disponibilidad de un mercado de trabajo y el mercado de productos intermedios entre las firmas. Mientras que en la segunda se introduce la externalidad restante conocida como "derrama de conocimiento y tecnología". Koo (2005) asume que ambas externalidades tienen un efecto directo sobre la productividad regional de las firmas.

A continuación se propone un esquema gráfico que muestra el mecanismo en que operan ambas externalidades y la relación con la productividad regional de la industria, como determinantes de la aglomeración de la industria manufacturera. Primeramente, aparecen tres variables del lado izquierdo, donde se enmarcan las dos fuentes marshallianas conocidas también como "externalidades pecuniarias". La primera está vinculada a la disponibilidad de mano de obra que se localiza geográficamente, donde la probabilidad de emplearse es alta, y es precisamente esta disponibilidad lo que provoca que una mayor cantidad de firmas se vea atraída para establecerse en dicho espacio y así la industria se aglomere. Las otras dos variables determinan la decisión de localizarse en función de la posibilidad que tienen las firmas de poder vender los productos que elaboran, los cuales son utilizados como insumos en el proceso productivo de la industria (encadenamientos de la demanda); y además, algunas firmas podrían beneficiarse de la proximidad geográfica con otras firmas, ya que podrían tener acceso a los productos que éstas ofrecen para utilizarlos en su proceso productivo con el objetivo de optimizar en términos de costos (encadenamientos de los costos). En este sentido, las relaciones comerciales entre las firmas locales se fortalecen, lo que provoca que se acelere la dinámica comercial de la región, estimulando la decisión de localización de nuevas firmas, y como resultado se observa un mayor nivel de concentración de la industria (figura 1).

La mayor dimensión de la industria, inducida por la accesibilidad de parte de las firmas a un mercado laboral denso y a la red de proveedores de insumos, da origen a las externalidades pecuniarias y a las externalidades tecnológicas. En el primer caso, las externalidades son impulsadas por el mercado a través de las economías de escala externas que se generan por la mayor interacción comercial entre las firmas. Mientras que las externalidades tecnológicas se generan a partir de un proceso circular que involucra la red de innovación tanto formal como informal entre las firmas, 
Figura 1. Los determinantes en la decisión de la localización de la industria manufacturera, en un contexto de economías externas y su efecto sobre la productividad

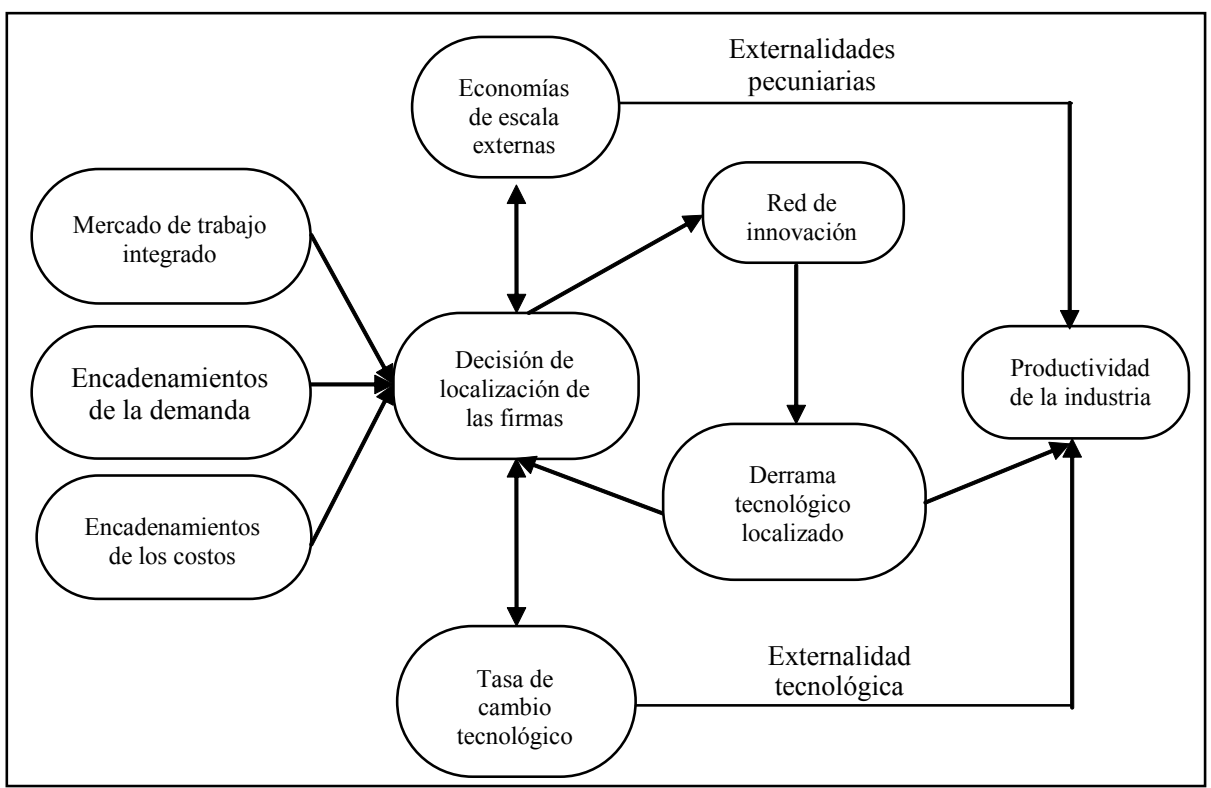

Fuente: Elaboración propia con base en Koo (2005).

la derrama tecnológica localizada y la misma aglomeración de la industria. Este proceso circular provoca que la tasa de cambio tecnológico se acelere dado que las firmas constantemente realizan mejoras tecnológicas a sus productos. En consecuencia, existen incentivos para que las firmas decidan localizarse en aquellos lugares donde constantemente se innova - la dimensión del mercado se incrementa- con el objetivo de permanecer actualizados respecto de los avances tecnológicos que se desarrollan en dicha lugar. $\mathrm{Al}$ mismo tiempo, el rápido cambio tecnológico conduce a una mayor concentración de las firmas (Koo, 2005).

En relación con el proceso circular que se presenta en la figura 1, éste se origina a partir del creciente número de firmas que deciden localizarse en un espacio específico, de tal forma que la industria se aglomera cada vez más. En dicho proceso de aglomeración, las firmas van creando redes 
de innovación, las cuales pueden ser formales o informales, y a través de éstas, se difunden los nuevos desarrollos tecnológicos y la innovación en los productos, por lo que se genera una derrama de conocimiento y de tecnología. Esto atrae a otras firmas que desean insertarse en este proceso de innovación y desarrollo tecnológico, incentivando nuevamente que la dimensión de la industria se incremente (Krugman, 1998). Sin embargo, de acuerdo con Koo (2005), es importante resaltar que el proceso circular que se genera a partir de las externalidades tecnológicas es sostenible bajo el supuesto de que la difusión del conocimiento y de la tecnología se encuentre localizada geográficamente.

En conjunto, las externalidades pecuniarias —a través de las economías de escala externas-y las externalidades tecnológicas —mediante la tasa de cambio tecnológico- provocan que las firmas de la industria sean más competitivas al concentrarse geográficamente como consecuencia de la mejora en la productividad. Este mecanismo es el que opera en la dinámica de la aglomeración de la industria manufacturera, fundamentalmente en la de media y alta tecnología, debido a que es más probable que las externalidades en cuestión surjan como consecuencia de la utilización de una gran cantidad de insumos entre las industrias, al hecho de que emplean trabajo calificado y a que innovan periódicamente tanto en diseño como en el desempeño de los productos. En este sentido existen incentivos para que la industria de alta tecnología se concentre.

Aunque en la figura propuesta no se expone el límite de la aglomeración y los cambios que se pueden dar en la estructura de las industrias que integran las actividades productivas de una región, se asume que cuando imperen condiciones como la poca disponibilidad territorial para la instalación de nuevas firmas, se observará un proceso dispersivo de las firmas o incluso de la industria que opera con rendimientos decrecientes o constantes a escala, esto debido a que la industria o firmas no son capaces de asumir los elevados costos de congestión que se manifiestan por la elevada concentración de industrias y la poca disponibilidad de espacio geográfico. Entonces, el sistema funciona de manera conjunta cuando la aglomeración de la industria no ha provocado elevados costos de congestión; en caso contrario, el único componente que continúa trabajando a favor de la mayor productividad, y en consecuencia de la aglomeración, son las externalidades tecnológicas. 
La tercerización de las economías desarrolladas corresponde al caso donde la aglomeración de la industria sólo es sostenible bajo externalidades tecnológicas, traduciéndose, por un lado, en una menor presencia de procesos de producción industrial, principalmente los de menores rendimientos a escala; y por otro, especializándose en la parte de la innovación del producto y el diseño. Estas economías están caracterizadas fundamentalmente por ser productivas, incorporar en los procesos de producción actividades de innovación, demandar mano de obra con mejores niveles de educación y pagar salarios más altos. De acuerdo con un reporte del Banco Mundial de 2009, en 120 ciudades de China se encontró evidencia que refleja que las industrias más productivas se ubican en las ciudades más congestionadas (World Bank, 2009).

\section{Los establecimientos manufactureros analizados en Matamoros y Reynosa}

De la evidencia empírica mostrada sobre el nivel de aglomeración de la industria de alta tecnología en pocos estados y ciudades de México, resulta relevante identificar los determinantes que definen su localización, con base en el esquema propuesto en el apartado previo. Los hallazgos permitirán identificar las razones por las que la industria de alta tecnología se concentra geográficamente. Para lograr tal fin se utilizará como unidad de análisis la frontera norte de Tamaulipas, específicamente las ciudades de Matamoros y Reynosa que, de acuerdo con la datos mostrados, tienen una presencia significativa.

Para dicho fin, se elaboró y aplicó un cuestionario a un conjunto de establecimientos manufactureros que pertenecen a la industria de alta tecnología. De estos resultados se derivan conclusiones integrales de las condiciones locales que promueven esta industria en la zona. El cuestionario se construyó tomando como referencia la Encuesta de Industria Mensual Ampliada que implementa el Instituto Nacional de Estadísticas y Geografía (INEGI), y con base en el cuestionario de Aprendizaje Tecnológico y Escalamiento Industrial (Carrillo y Gomis, 2004).

Tomando como base la aplicación del cuestionario a establecimientos de producción localizados en las ciudades de Reynosa y Matamoros durante el 
periodo de agosto de 2010 a marzo de 2011 , se obtuvo información precisa en cuanto a la estructura corporativa, inversión, aspectos institucionales, investigación, innovación en productos, desarrollo tecnológico, tecnologías de la información y comunicación, decisión de localización, características laborales, producción y los encadenamientos productivos. El cuestionario tiene una extensión de 13 páginas, las cuales agrupan un total de 135 preguntas. ${ }^{2}$ Este instrumento fue diseñado para obtener información que permitiera definir los factores que determinaron la localización de la industria de alta tecnología en la frontera norte del estado de Tamaulipas a partir del esquema que se presentó previamente.

Los establecimientos manufactureros se ordenaron con base en el Sistema de Clasificación Industrial de América del Norte (SCIAN), por nivel de clases. A partir de dicha clasificación se seleccionaron las plantas de producción que pertenecen al sector electrónico, eléctrico y del transporte. Se agrupó un total de 111 unidades económicas, en Reynosa 70 y en Matamoros 41. Sin embargo, no fue posible realizar la aplicación de la encuesta a todas las unidades económicas por razones como el desinterés por contestar el cuestionario, porque iba en contra de la política del establecimiento o por falta de tiempo para contestar el cuestionario, entre otras razones. En consecuencia, únicamente se aplicó el cuestionario a 36 establecimientos en Reynosa y a 19 en Matamoros. La distribución a través de las tres industrias de alta tecnología se muestra en el cuadro 3.

Para Matamoros se tuvo un nivel de respuesta de $46 \%$ y en el caso de Reynosa de $51 \%$. En conjunto se tuvo un nivel de respuesta de $50 \%$. Sin embargo, la desigual distribución de plantas de producción encuestadas entre las tres industrias y entre las dos ciudades limita la posibilidad de analizar los factores que intervienen en su localización de manera separada. Por lo tanto, el análisis se realizará preponderantemente considerando a ambas ciudades y a la tríada de industrias en conjunto.

Cabe resaltar que el cuestionario fue contestado por encargados legales de la unidad económica, gerentes de recursos humanos, gerentes de producción y gerentes de import-export. A continuación se muestra la lista de establecimientos a los cuales se les aplicó el cuestionario: Ametek, Andrew, BвB, Bettcher Manufacturing, Black \& Decker, Brose, Cinch, CRH, Cedro,

\footnotetext{
${ }^{2}$ Cuestionario disponible en formato electrónico para quien así lo requiera.
} 
Cuadro 3. Distribución de las industrias encuestadas en Matamoros y Reynosa

\begin{tabular}{|l|c|c|c|}
\hline & Matamoros & Reynosa & Total \\
\hline Industria electrónica & 7 & 14 & 21 \\
\hline Industria eléctrica & 7 & 12 & 19 \\
\hline Industria del transporte & 5 & 10 & 15 \\
\hline
\end{tabular}

Fuente: Elaboración propia.

Cequent Electrical Products, Closures Interiors, Coil Company, Componentes Universales, Controles Reynosa, Corning Cable and System, Delinc, Delphi Matamoros, Delphi Reynosa, Decofinmex, Eaton, Emerson Tool and Appliance, Caterpillar, Ensambladora de Motores, Erika Reynosa, Fisher \& Paykel Appliances Products, Fisher Dynamics, Fox Conn, Fujitsu Ten, Grand Product, Hs Electronics, Ilsco, Invensys, Imax, Kemet, Kimball, LG Electronics, Lamosa, Landis \& Gys, Lineage Power, Mikuni, Nokia, Panasonic, Porta System, Revcor, Semtech, Simclar, Sociedad de Motores Domésticos-gem, Spellman, Standard Motor Product de México, Starkey, Tenneco, TRW, Tecnologías Médicas Innovadoras, Victoreen y Wells.

Determinantes de la aglomeración de la industria manufacturera de alta tecnología en Matamoros y Reynosa

\section{Estructura corporativa y la perspectiva de inversión}

De los establecimientos encuestados, 12 iniciaron sus operaciones entre 1967 y 1986, distribuidos equitativamente entre Matamoros y Reynosa. En lo referente al periodo de 1987 a 1997, el total de establecimientos de alta tecnología que iniciaron operaciones en estas ciudades fue de 21 , de las cuales 16 se ubicaron en Reynosa y 5 en Matamoros. Este mismo ritmo de crecimiento continuó durante el periodo de 1998 a 2008 donde se observaron 22 nuevos establecimientos, de los cuales 8 se localizaron en 
Matamoros y 14 en Reynosa. Esto significa que en las últimas dos décadas la localización de establecimientos manufactureros de alta tecnología en estas dos ciudades se incrementó en $258 \%$, incluso creciendo por encima de la industria intensiva en mano de obra (De la Garza, 2004).

En lo referente al origen de la inversión en capital por parte del corporativo, $100 \%$ de los establecimientos manifestó contar con participación extranjera. Incluso, en algunos casos, la inversión provenía de varios países, por lo que la distribución del origen de la inversión extranjera, que a continuación se presenta, no corresponde al total de 55 establecimientos manufactureros encuestados. Así, la inversión extranjera de los establecimientos se distribuyó de la siguiente manera: 41 empresas manifestaron contar con capital de Estados Unidos, 4 de Canadá, 5 de Japón, 4 de China, 2 de Corea, 4 de Alemania, 1 de Escocia, 1 de Finlandia, 1 de Nueva Zelanda y 1 de Suiza. Esto significa que en tres cuartas partes de los establecimientos el capital proviene de Estados Unidos.

Es de llamar la atención que del total de establecimientos encuestados, $44 \%$ fue consecuencia de una relocalización, lo que significa que anteriormente habían estado localizados en otro lugar. Al cuestionarles sobre su ubicación previa, $41 \%$ manifestó haber estado establecidos en Estados Unidos y $44 \%$ en otra ciudad de México. En el caso de México se observó que procedían de Aguascalientes (1), Apodaca (1), Ciudad Juárez (1), Distrito Federal (1), Mesquite (1), Matamoros (2), Mexicali (1), Nogales (1), Nuevo Laredo (1), Reynosa (1) y Tijuana (2). De Estados Unidos de ciudades como Cleveland (1), Huntington (1), Kent (1) y McAllen (1).

Que una proporción significativa de establecimientos haya estado ubicada en otra parte previa a su localización actual, en Matamoros y Reynosa, representa un elemento interesante en cuanto al papel que ha desempeñado el estado de Tamaulipas, y particularmente estas dos ciudades, en la concentración de más industria de alta tecnología. Y es de mayor relevancia el hecho de que la relocalización provenga de otras ciudades, principalmente fronterizas del norte de México, lo que podría representar que en estas ciudades, y en especial Reynosa, existen mejores condiciones para desempeñar sus actividades productivas, sobre todo por el hecho de que los requerimientos de tiempos de entrega para estos establecimientos son prioritarios, por lo que buscan principalmente localizarse cerca de sus proveedores y clientes (Unger y Chico, 2004; Sargent, 2003). 
En cuanto a la expectativa que prevalece sobre el crecimiento de la inversión en la actividad que desarrolla, en el caso de Matamoros, 37\% espera que se presenten nuevas inversiones en esta industria, mientras que en Reynosa el porcentaje es mucho mayor, ya que $81 \%$ espera que la industria a la que pertenece continúe creciendo. En cuanto a la inversión que se espera realizar sobre el establecimiento, en Matamoros, $79 \%$ manifestó que espera que el establecimiento se amplíe; $11 \%$ considera que es posible que se abran nuevos establecimientos en la ciudad; y 5\% espera que abra un establecimiento en otra parte de México. El panorama para Reynosa es distinto: $70 \%$ espera que se amplíe el establecimiento; $28 \%$ espera que se abra una nueva planta en la ciudad; y $17 \%$ que se abra una nueva planta en otra parte de México. Este resultado permite establecer que en Matamoros se espera que los establecimientos amplíen su capacidad productiva, a diferencia de Reynosa, donde se espera una mayor apertura de nuevas plantas de producción de alta tecnología. Con lo cual, la escala de producción para Matamoros se incrementaría a partir de un crecimiento del establecimiento; es decir, se mejorarían las economías de escala al interior, mientras que en Reynosa la escala se ampliaría a partir de una mayor presencia de establecimientos, lo que podría reflejarse en la presencia de economías de escala externas. Si estas expectativas se cumplieran, la mayor concentración de industria de alta tecnología en la ciudad de Reynosa, bajo ciertas condiciones, podría obedecer a la presencia de economías externas.

La cantidad de establecimientos que comentó que no espera que en un futuro se relocalice a otra ciudad conforma 91\%. Aunque $74 \%$ manifestó que su decisión de localización está asociada fuertemente con la competitividad observada en China, lo que significa que China en la actualidad no solamente tiene ventaja salarial en industrias intensivas en mano obra sino también en aquellas que elaboran productos de alta tecnología.

Las principales razones que podrían provocar que el establecimiento se relocalizara a otro lugar son: encarecimiento de la mano de obra, inseguridad, problemas con el sindicato, los clientes migren a China, tipo de cambio y los cambios en la regulación arancelaria.

En cuanto a la antigüedad promedio de la maquinaria y equipo empleados en la producción, en 14 establecimientos se tiene menos de 5 años de antigüedad. Entre 5 y 10 años un total de 22 establecimientos 
manufactureros; y más de 10 años un total de 18. En cuanto a la frecuencia con la que se realizan las mejoras en maquinaria y equipo de producción, 53\% mencionó que se realizan más de una vez al año, mientras que $25 \%$ solamente una vez al año. Por su parte, en cuanto a la mejora de los sistemas de producción, que son precisamente los que administran la actividad productiva de los establecimientos, $47 \%$ expresó que se realizan mejoras más de un vez al año y $38 \%$ únicamente realiza mejoras en los sistemas una vez al año; en el resto no se hacen mejoras o en algunos casos no se respondió la pregunta.

El panorama mostrado en cuanto al reemplazo y mejora de maquinaria, equipo y sistemas de información en la industria de alta tecnología corresponde, en cierta medida, con los requerimientos de producir bienes cada vez más sofisticados, ya que aproximadamente $80 \%$ de los establecimientos realiza mejoras una vez al año en la maquinaria, equipos y sistemas de información. Además, la maquinaria empleada en el proceso de producción en $65 \%$ de los establecimientos es menor a 10 años.

En conjunto, la dinámica de crecimiento de la región se aceleraría si la industria frecuentemente realizara mejora en su maquinaria, equipo y sistemas de información. Sin embargo, este crecimiento se polariza si la maquinaria y equipo que se remplaza no se adquiere en el país. Para el caso de las ciudades analizadas, un total de 46 establecimientos manufactureros expresó que menos de $10 \%$ de la maquinaria y equipo que se utiliza en sus establecimientos se adquirió en México.

\section{Mercado objetivo de la industria de alta tecnología localizada en Matamoros y Reynosa}

De las empresas que consideraron que localizarse en estas ciudades no es con el objetivo de satisfacer la demanda local de sus productos, suman $56 \%$, mientras que $38 \%$ consideran que sí lo hacen para cubrir la demanda local. Sin embargo, $98 \%$ de los establecimientos mencionados se localizan en estas ciudades con el objetivo de abastecer al mercado de Estados Unidos.

El hecho de que la inversión principalmente provenga de Estados Unidos y que gran parte de su producción se destine a este mercado lo 
hace vulnerable a un conjunto de situaciones. Tal es el caso de los choques que se pueden presentar en esta economía, al menos ésta es la percepción de $87 \%$ de los establecimientos manufactureros, después de la contracción de la economía de Estados Unidos observada a finales de 2008 y principios de 2009. Por otro lado, al ser éste su principal mercado, un factor clave para la localización de su establecimiento manufacturero son los tiempos de cruce entre México y Estados Unidos, según $82 \%$ de los establecimientos. Y finalmente, el debilitamiento de los encadenamientos como consecuencia directa de que el mercado para los productos que elaboran las industrias de alta tecnología se destina a otra región y/o país.

Cabe hacer mención que la poca relevancia con la que ponderaron los establecimientos manufactureros a la disponibilidad de infraestructura física, como un determinante en su localización, se debió a que al estar estos establecimientos integrados al mercado de Estados Unidos, no requieren de mayor y mejor infraestructura carretera, ferroviaria y aérea. Aunque la disponibilidad y las condiciones de la infraestructura física urbana sí los impacta directamente.

\section{Logística de la producción y el transporte}

En promedio, los establecimientos manufactureros encuestados en estas ciudades elaboran 309 productos diferentes; sin embargo, hay empresas que llegan a producir hasta 7 mil productos diferentes. Haciendo referencia a su principal producto que elaboran, 53 de 55 establecimientos manifestaron que requieren, en promedio, un total de 273 insumos para su producción. En 53\% de los establecimientos su principal producto es intermedio. Sin embargo, únicamente $3 \%$ de estos productos intermedios se utiliza en la elaboración de algún otro producto en estos establecimientos.

Cabe hacer mención que $71 \%$ de los establecimientos manufactureros de alta tecnología se beneficia de la localización de otros establecimientos que prestan servicios outsourcing. Los servicios outsourcing que comúnmente se utilizan en el proceso de producción son el pintado, retrabajo (separación de insumos por defectos en el proceso de producción) y herramientas.

En cuanto a la distribución de la producción en el mercado, $75 \%$ de los establecimientos envía entre $60 \%$ y $100 \%$ de la producción de su principal 
producto a un centro de distribución y logística. En cuanto a estos centros, $85 \%$ se ubica en Estados Unidos, principalmente en Texas, y el resto en México, específicamente en la Ciudad de México, Estado de México y Tamaulipas. Del total de establecimientos que no envían el $100 \%$ de la producción a un centro de distribución y logística, es decir 29, 7 únicamente comercializan directamente el principal producto que elaboran. De estos 7, sólo 1 de ellos manifestó que $100 \%$ de la producción de su principal producto se vende en México, específicamente en Matamoros; otro, el 10\%; y 2 más, sólo 1\%. El resto, a otras partes del país.

En consecuencia, enviar la mayoría de la producción de los establecimientos encuestados a los centros de distribución y logística implica incurrir en costos de transporte, por lo que se vuelve un elemento determinante en la decisión de la localización. Así, 85\% de los establecimientos manufactureros considera que ubicarse en estas ciudades les permite disminuir los costos de transporte, mientras que la proporción restante comentó que no tiene impacto. Ahora bien, en promedio, $45 \%$ de los servicios de transporte utilizados por los establecimientos se ubica en estos municipios, por lo que el sector transporte se beneficia de la concentración de estas industrias de alta tecnología.

\section{Características del personal ocupado de la industria de alta tecnología}

El número total de trabajadores de planta y eventuales que laboraron en 2010 en ambas ciudades en los 55 establecimientos es 49 896, de los cuales a Matamoros le corresponden 14214 y a Reynosa 35 682. Como consecuencia de la crisis mundial a finales de 2008, dejó de trabajar un total de 20382 empleados en 2009, de los cuales 12201 fueron trabajadores directos mientras que 8181 fueron indirectos. En general, la industria manufacturera, para el caso de México, fue la que mayor efecto resintió de la contracción mundial, particularmente la altamente integrada con la economía de Estados Unidos.

La distribución porcentual de los trabajadores directos respecto del nivel de estudios técnicos es $24 \%$; licenciatura o ingeniería $10 \%$; y menos de $1 \%$ tiene posgrado; es decir, que $65 \%$ de los trabajadores únicamente 
cuenta con educación básica. Lo que significa que la industria de alta tecnología que se encuentra instalada tanto en Matamoros como en Reynosa emplea trabajadores con baja calificación, como también se observa en los resultados mostrados por De la Garza (2004). Plaut y Pluta (1983) exponen que esto se debe a que las ventajas tecnológicas y la creciente rutina de muchas tareas industriales han reducido la necesidad de que los establecimientos busquen trabajadores altamente entrenados y educados. De hecho, manifiestan que las industrias podrían localizarse y expandirse en áreas con poca educación y poco trabajo calificado debido a que aquéllos desempeñan tareas simples con menos resistencia. En este sentido, es comprensible observar que un alto porcentaje de los establecimientos manufactureros, es decir 98\%, pondera que el acceso a mano de obra barata es determinante en la definición de su localización, por lo que la mayor presencia de industria más tecnificada no se ha traducido en una mayor participación de trabajo más calificado, al menos la evidencia en Matamoros y Reynosa esos resultados arroja.

Por otro lado, la industria de alta tecnología encuestada capacitó en 2009 a un total de 29835 trabajadores; esto es, a 60\% de los trabajadores, los cuales se desempeñan principalmente en el área de producción y calidad. Además, los establecimientos manufactureros apoyan un total de 3087 trabajadores para realizar estudios de educación superior. Esta capacitación técnica es producto de la derrama de conocimiento de este tipo de industria; aunque bajo las condiciones de bajo nivel educativo de la mayoría de los trabajadores en la industria, los beneficios de esas derramas de poco contribuyen a mejorar la productividad de la industria (Dutrénit y Vera-Cruz, 2009).

Efectivamente, como lo mencionan Dutrénit y Vera-Cruz (2009), la mayor presencia de industrias que han acumulado capacidades tecnológicas en México ha contribuido a elevar la capacitación así como la preparación profesional de los trabajadores, fortaleciendo la formación de capital humano. Sin embargo, para la industria de alta tecnología localizada en Matamoros y Reynosa esto no puede convertirse en una ventaja de economías externas, al menos en el sentido de derrama de conocimiento y la creación de un mercado de trabajo integrado, ya que su perspectiva poco se aparta de los incentivos de localización de la industria intensiva en trabajo, limitando la mejora de la productividad de 
la industria en el sentido que se muestra en el esquema teórico del apartado previo.

Asimismo, se identificaron las acciones o actitudes más frecuentes de los trabajadores directos que desincentivan la decisión de los establecimientos de permanecer localizados en esta ciudad, las cuales son: falta de compromiso y ausentismo en $44 \%$ de los establecimientos; $12 \%$ por el problema de la rotación del personal; y en menor proporción, falta de experiencia, falta de mano de obra, migración de los trabajadores a su lugar de origen, falta de interés de autodesarrollarse, resistencia al cambio y el robo "hormiga".

\section{Investigación y derrama de conocimiento}

Las industrias que elaboran productos de alta tecnología permanentemente se encuentran inmersas en un proceso de mejora de sus productos, así que la investigación y el desarrollo tecnológico son fundamentales. Éstas deciden concentrarse en regiones donde se localizan sus competidores, no solamente para acceder al mercado de bienes, servicios, de empleo capacitado o a mejor infraestructura pública, sino también para acceder a la generación de nuevas ideas que les permita mantener a la vanguardia sus productos (World Bank, 2009). También se concentra con el objetivo de conocer las actividades de investigación y desarrollo tecnológico que implementa su competencia.

Para conocer la dinámica de innovación de los establecimientos manufactureros de alta tecnología, se elaboró el Índice de Innovación (Indino) a partir de las preguntas 10.4, 10.5 y la 10.6 del cuestionario aplicado a todos los establecimientos. La primera pregunta cuestionaba: “¿En qué año se empezaron a elaborar en esta planta los tres principales productos que fabrica? (No importa haber estado localizado en otro punto dentro de la ciudad)"; la pregunta 10.5 planteaba: "Desde que se empezaron a elaborar los tres principales productos en esta planta hasta la actualidad, ¿se han realizado cambios a la versión original?”; y la tercera preguntaba: "¿Cuántas versiones diferentes de los tres principales productos que elaboraba han existido?”. Para el cálculo del índice únicamente se tomó en cuenta la respuesta del principal producto que elaboraba cada uno 
Jorge Pérez, Guadalupe Ceballos, y Adolfo Cogco/Los factores que explican la mayor aglomeración

de los establecimientos encuestados; el índice se formuló de la siguiente manera:

$$
I N D I N O=\left(\frac{\text { número de versiones diferentes del producto }}{\text { años que lleva produciendolo el establecimiento }}\right)
$$

El resultado representa el número promedio anual de versiones diferentes que ha tenido el principal producto elaborado por el establecimiento desde que se inició su producción. Los resultados muestran que $66 \%$ de los establecimientos, de un total de 38 que han realizado cambios a la versión original de su principal producto, manifestó que han realizado en promedio menos de una innovación en su principal producto por año; mientras que $21 \%$ realiza innovaciones al producto en promedio entre una y cinco veces al año; e innovaciones de más de seis veces por año se observaron en $13 \%$ de los establecimientos. Este resultado refleja que la mayoría de los establecimientos realiza muy pocas innovaciones en sus productos por años, y sólo un total de 13 establecimientos realiza más de una innovación al año. En un sentido estricto, únicamente cinco establecimientos innovan de manera permanente, que son los que respondieron mejorar sus productos más de seis veces por año. En este sentido, la baja innovación de la mayoría de los establecimientos no hace viable la conformación de una red informal de innovación que actúe a favor de un sistema que genere condiciones favorables para la localización de una mayor proporción de establecimientos que permitan ir mejorando la escala de producción de la industria y que esto pueda manifestarse en una mejor productividad de la industria a través de las externalidades pecuniarias y tecnológicas, tal como se muestra en la figura presentada previamente.

Sin embargo, aun cuando se observan innovaciones en 38 de los 55 establecimientos encuestados, la evidencia hallada muestra que sólo $27 \%$ de los establecimientos de producción localizados en los municipios realiza actividades de investigación y desarrollo tecnológico, lo que significa un total de 15 de 55. Específicamente, en Matamoros se observa que $21 \%$ realiza estas actividades y en Reynosa $31 \%$. De los 15 establecimientos que realizan investigación, solamente 2 han desarrollado patentes, una en Matamoros y otra en Reynosa. En Matamoros, el establecimiento 
únicamente ha desarrollado una patente mientras que en Reynosa el establecimiento ha desarrollado 50 patentes. El registro de las patentes se ha realizado en Estados Unidos. Así que la gran mayoría de los establecimientos que realizan innovaciones en sus productos no desarrolla la investigación en el establecimiento.

El diseño del principal producto que elaboran para $80 \%$ de los establecimientos localizados en estas ciudades se desarrolla fundamentalmente en Estados Unidos; $13 \%$ lo realiza en otra parte del mundo, y solamente $6 \%$ diseña su producto en estas ciudades. De igual forma, los establecimientos que no realizan investigación en estas ciudades expresaron que la desarrollan principalmente en Estados Unidos.

Los resultados encontrados tampoco permiten establecer que existe evidencia a favor de la derrama tecnológica entre los establecimientos de alta tecnología localizados en estas dos ciudades. Esto debido a que únicamente 7 de los 15 establecimientos que realizan investigación manifestaron haberse beneficiado de la investigación realizada por otros establecimientos, uno localizado en otra parte del país y los otros 6 en otras partes del mundo. Ahora bien, de los resultados en relación a si otros establecimientos se han beneficiado de la investigación que realiza el establecimiento, se encontró que 6 de los 15 establecimientos respondieron que sí, de los cuales 3 se ubican en alguno de los municipios y 3 en el resto del país. Sin embargo, este resultado no es concluyente debido a que no es posible afirmar que los establecimientos beneficiados pertenezcan a la industria de alta tecnología, más aún si se considera que cada uno de los establecimientos encuestados produce en promedio 309 productos, por lo que es difícil establecer sobre qué producto se están beneficiando los demás establecimientos y si estos últimos pertenecen a la industria de alta tecnología.

Bajo este panorama de poca investigación, innovación y nula derrama tecnológica entre los establecimientos manufactureros de alta tecnología, se jerarquizan algunas razones que dificultan las actividades de investigación, tales como la carencia local de centros de investigación, insuficiente infraestructura física de la planta, la falta de personal calificado en la ciudad y la poca investigación en otras plantas locales, cada una de ellas denota la poca relevancia que se le da en México al tema de la investigación y desarrollo (De la Garza, 2004). La vinculación de los establecimientos 
manufactureros con los institutos y centros educativos superiores se ve obstruida, de acuerdo con el $43 \%$ de los establecimientos, por la falta de infraestructura en dichas instituciones o centros, lo que afecta y obstruye la colaboración en actividades de investigación y capacitación. Aunque $31 \%$ de los establecimientos considera que la desconfianza en la discrecionalidad institucional sobre las actividades de investigación que desarrolla el establecimiento es otro factor que también afecta su vinculación.

\section{Encadenamientos productivos}

La industria de alta tecnología localizada en estos dos municipios requiere, en promedio, 273 productos para la elaboración del principal producto. $\mathrm{Al}$ menos éste es el caso para 53 de las 55 plantas encuestadas. Sin embargo, existe un establecimiento que requiere hasta 9 mil insumos y otro, mil insumos. Lo anterior significa que estas industrias se relacionan con varios establecimientos para la adquisición de sus insumos, lo que hace interesante su análisis en términos de la importancia que representan para la dinámica de crecimiento y desarrollo de las regiones. Cabe mencionar que esta dinámica surge y se acelera cuando los establecimientos se encadenan con la industria localmente; en caso contrario no genera incentivos adicionales al crecimiento y al desarrollo regional y por lo tanto la aglomeración de la industria de alta tecnología obedece a otros factores distintos a los encadenamientos productivos (Dávila, 2004; Hanson, 1994; Hirschman, 1979), al menos desde la perspectiva del esquema propuesto anteriormente.

La evidencia hallada en Matamoros y Reynosa señala que los encadenamientos no operan como un factor determinante en la concentración de la industria de alta tecnología, debido a que en más de la mitad de los establecimientos manufactureros de alta tecnología (específicamente en $52 \%$ ), $100 \%$ de los insumos utilizados en el principal producto que elabora el establecimiento proviene de un centro de distribución y logística. De hecho, $31 \%$ de las plantas manifestó directamente que su localización no estaba definida en función del acceso a insumos locales. Cabe mencionar que $70 \%$ de estos establecimientos pertenece al corporativo.

De manera general, considerando todos los productos que elaboran los establecimientos estudiados, en el cuadro 4 se muestra el porcentaje 
Cuadro 4. Porcentaje de proveedores de insumos localizados en Matamoros y Reynosa

\begin{tabular}{|c|c|}
\hline Porcentaje de proveedores & $\%$ \\
\hline 0 & 29.09 \\
\hline 1 & 10.91 \\
\hline 2 & 3.64 \\
\hline 3 & 5.45 \\
\hline 4 & 1.82 \\
\hline 5 & 16.36 \\
\hline 8 & 1.82 \\
\hline 10 & 10.91 \\
\hline 15 & 3.64 \\
\hline 20 & 7.27 \\
\hline 30 & 5.45 \\
\hline 100 & 1.82 \\
\hline No sabe & 1.82 \\
\hline
\end{tabular}

Fuente: Elaboración propia.

de proveedores de insumos de estos establecimientos que se localizan en estos municipios.

Como se observa en el cuadro 4, 67\% de las plantas localizadas en los municipios analizados manifestó que únicamente $5 \%$ de sus proveedores se localiza en estos municipios, mientras que, aproximadamente, una tercera parte de las plantas no cuenta con proveedores locales. Solamente una planta manifestó que $100 \%$ de sus proveedores se localiza en estos municipios. Si se descarta este último nivel, el máximo nivel de porcentaje de proveedores locales con los que cuentan los establecimientos de producción es de 30\%. La mayoría de las plantas, es decir 80\%, manifestó que el porcentaje de proveedores locales apenas alcanza 10\%. Este resultado es consistente en lo planteado en Dutrénit y Vera-Cruz (2009), que exponen que ha existido un avance en la acumulación de capacidades tecnológicas de la industria maquiladora; sin embargo, en el tema referente al crecimiento en la participación de proveedores locales se ha visto limitada. 
Ahora bien, 4 de los 38 establecimientos manufactureros que expresaron tener proveedores en estos municipios manifestaron que no son nacionales, mientras que 7 establecimientos que tienen proveedores locales expresaron que entre $1 \%$ y $40 \%$ son nacionales; 9 , entre $50 \%$ y $90 \%$; y finalmente, 16 establecimientos manufactureros comentaron que, de la proporción de proveedores locales, $100 \%$ es nacional. Sin embargo, este resultado, aunque es alentador para el impulso de proveedores locales, no mitiga la ausencia de encadenamientos productivos observados en los dos municipios.

Las plantas enumeraron, en orden de importancia, los factores que han obstaculizado las relaciones con proveedores locales mexicanos de insumos: 1. los proveedores no fabrican lo que necesitan; 2. los elevados precios de los insumos; 3. los tiempos de entrega; 4. se carece de información sobre proveedores locales; 5 . falta de interés del corporativo; 6 . la mala calidad de los productos; 7 . poca diversidad de productos; 8 . falta de capacidad productiva de los proveedores; y 9. escasa innovación sobre sus productos.

Bajo este contexto, la industria de alta tecnología localizada tanto en el municipio de Matamoros como en el de Reynosa no ha promovido un mecanismo virtuoso que dé lugar a una concentración de industria que se caracterice por integrarse localmente a través del intercambio comercial. Entonces, siendo éste un elemento central que explica la formación de las aglomeraciones y la dinámica de los procesos de innovación y desarrollo tecnológico, que en conjunto generan espacios territoriales productivamente competitivos, como se explica en el esquema propuesto, será difícil observar el surgimiento de beneficios derivados de las economías externas y un continuo proceso de aglomeración de la industria de alta tecnología en estos municipios.

\section{Conclusiones}

El panorama derivado de la aplicación del cuestionario sobre los determinantes en la localización de la industria de alta tecnología en establecimientos manufactureros permitió poner en contexto las condiciones bajo las cuales opera la industria en las ciudades de Matamoros y Reynosa. 
De una manera, contribuyó a establecer las razones que tiene la industria para concentrarse en estas dos ciudades; y de otra, para conocer si estas razones se asocian a factores que son señalados en la Nueva Geografía Económica como determinantes de la localización de la industria, centrándose particularmente en los determinantes que se muestran en el esquema propuesto.

Los establecimientos manufactureros que se localizaron en estas ciudades procedentes de una ubicación previa en Estados Unidos son el reflejo del proceso de cambio en la vocación productiva de ese país, transitando de una economía industrial a una economía terciarizada. Al respecto, México, y en particular las ciudades de Matamoros y Reynosa, ha representado una opción favorable para su localización debido a que la proximidad con Estados Unidos les permite reducir costos de transporte y tiempos de entrega, así como tener acceso a mano de obra barata, prerrogativas fiscales y a la disponibilidad de infraestructura física adecuada. Cabe resaltar que estos factores incentivan la localización de la totalidad de las industrias encuestadas.

Como consecuencia de la integración de estos establecimientos manufactureros con el mercado de Estados Unidos se observa la débil o nula presencia de encadenamientos insumo-producto entre la industria de alta tecnología, aun cuando se observa que esta industria fabrica una gran cantidad de productos y que además demanda, en la misma medida, insumos intermedios. Esta situación, indudablemente, obstruye el mecanismo que se propuso para explicar la aglomeración de la industria de alta tecnología en Matamoros y Reynosa, el cual explica cómo se va creando y fortaleciendo la aglomeración de la industria con base en los beneficios que se generan por el tamaño de las economías externas. Sin embargo, también la ausencia conjunta de un denso mercado laboral calificado y de una red informal de establecimientos manufactureros que realicen actividades de investigación, diseño y desarrollo tecnológico han contribuido a que dicho mecanismo no genere incentivos vías las economías externas para la mayor aglomeración de la industria de alta tecnología.

Bajo este contexto, es posible establecer que el crecimiento de la industria de alta tecnología en las ciudades de Matamoros y Reynosa, ubicadas en la frontera norte de Tamaulipas, no obedece a la presencia de un crecimiento de la productividad de la industria vía la presencia de externalidades 
pecuniarias y/o tecnológicas, donde estas últimas no surgen debido a que no hay encadenamientos productivos, no hay derrama de conocimiento, el mercado laboral es no calificado y a que la investigación del principal producto del establecimiento se realiza en el corporativo.

Por el contrario, la industria de alta tecnología ha crecido en estas ciudades debido, principalmente, a la cercanía con Estados Unidos donde, en la mayoría de los casos, se envía la producción de la industria y de donde provienen los insumos empleados en su producción. Lo que significa que los tiempos de entrega (just in time) son fundamentales en la decisión de la localización. También, el acceso a mano de obra barata no calificada, los incentivos fiscales, la disponibilidad de infraestructura física urbana y el bajo costo de transporte han determinado su localización.

A pesar de que existen investigaciones donde se menciona que la industria maquiladora de exportación ha evolucionado en los últimos años (De la Garza, 2004; Dutrénit y Vera-Cruz, 2009; Carrillo y Gomis, 2004; Carrillo y Lara, 2004), transitando de una industria intensiva en mano de obra a una industria más tecnificada que realiza actividades de investigación, diseño y desarrollo tecnológico, al menos en el caso de Matamoros y Reynosa, donde se observa un crecimiento significativo de esta industria en la elaboración de productos de alta tecnología, no se encontró evidencia de dicha evolución.

Finalmente, es importante señalar que las instituciones públicas encargadas del crecimiento y desarrollo de las economías locales deben impulsar estrategias que promuevan la generación de inversión que no se fundamente únicamente en la generación de empleos, sino también que tal inversión impulse el crecimiento de la economía a través de una estructura productiva integrada localmente que permita elevar la productividad de la industria manufacturera y del resto de los sectores productivos para, así, elevar la competitividad tanto en el entorno nacional como internacional. La interacción del sector educativo y científico con el sector productivo es fundamental para garantizar el crecimiento y desarrollo económicos.

\section{Bibliografía}

Carrillo, J. y Gomis, R. (2004). La maquiladora en datos: Resultados de una encuesta sobre tecnología y aprendizaje. Tijuana, México: El Colegio de la Frontera Norte. 
Carrillo, J. y Lara, A. (2004). Nuevas capacidades de coordinación centralizada: ¿Maquilas de cuarta generación en México?, Estudios, (003), 647-667.

Chatterjee, S. (2003). Agglomeration economies: The spark that ignites a city?, Business Review, 4, 6-13.

Dávila, F., A., (2004). México: Concentración y localización del empleo manufacturero, 1980-1998. Economía Mexicana, XIII(002), 209-254.

De la Garza, E. (2004). Modelos de producción en el sector maquilador: Tecnologías, organización del trabajo y relaciones laborales. Documento presentado en el Ix Foro de Investigación: Congreso Internacional de Contaduría, Administración e Informática, unam, México.

Dutrénit, G. y Vera-Cruz, A. O. (2009). Derramas de conocimiento hacia las instituciones: El caso de Ciudad Juárez. En G. Dutrénit (Coord.), Sistemas regionales de innovación: Un espacio para el desarrollo de las Pymes. El caso de la industria de maquinados industriales, (pp. 194-215). México: UAm, Textual.

Ellison, G. y Glaeser, E. (1999). The geographic concentration of industry: Does natural advantage explain agglomeration?, The American Economic Review, 89(2), 311-316.

Fujita, M., Krugman, P. y Venables, A. (1999). The Spatial Economy. Cambridge: The мIT Press.

Fujita, M. y Thisse, F. (2002). Economies of agglomeration, cities, industrial location and regional growth. Reino Unido: Cambridge University Press.

Galbraith, C., De Noble, A. y Estavillo, P. (1990). Location criteria and perceptions of regional business climate: A study of mexican and U. S. small electronics firms, Journal of Small Business Management, 28(4), 34-47.

Hanson, G. (1994). Regional adjustment to trade liberation, National Bureau of Economic Research. (Documento de Trabajo núm. 4713). Cambridge, Massachusetts.

Hirschman, A. O. (1979). La estrategia del desarrollo económico. México: Fondo de Cultura Económica.

Kaldor, N. (1970). The case for regional policies. Scottish Journal of Political Economy, $17,337-48$.

Koo, J. (2005). Technology spillovers, agglomeration, and regional economic development. Journal of Planning Literature, 20(2), 99-115.

Krugman, P. (1991). Geography and Trade. Cambridge: мiт Press.

Krugman, P. (1998). What's new about the new economic geography?, Oxford Review of Economic Policy, 14(2), 17.

Lösch, A. (1954). The economics of location. New Haven: Yale University Press.

Marshall, A. (1920). Principles of economics (8va. ed.). Londres: Macmillan.

Mendoza, J. y Pérez, J. (2007). Aglomeración, encadenamientos industriales y cambios en la localización manufacturera en México. Economía, Sociedad y Territorio, 6(23), 655-691. 
Jorge Pérez, Guadalupe Ceballos, y Adolfo Cogco/Los factores que explican la mayor aglomeración

Organización para la Cooperación y el Desarrollo Económicos y Eurostat. (2005). Oslo manual: Guidelines for collecting and interpreting innovation data (3ra. ed.). París, Francia: Autor.

Plaut, T. y Pluta, J. (1983). Business climate, taxes and expenditures and state industrial growth in the U. S. Southern Economic Journal, 50, 99-119.

Sargent, J. (enero, 2003). Charter evolution in maquiladoras: A case study of Reynosa, Tamaulipas. (Documento de Trabajo 2003-16). Texas: University of Texas Pan American.

Unger, K. y Chico, R. (2004). La industria automotriz en tres regiones de México. Un análisis de clusters. El Trimestre Económico, LXXXI(4), (284), 909-941.

Weber, A. (1929). The theory of the location of industries. Chicago: Chicago University Press.

World Bank. (2009). Informe sobre el desarrollo mundial 2009: Una nueva geografía económica. Banco Internacional de Reconstrucción y Fomento. Washington, Distrito de Columbia: Banco Mundial. 